\title{
Motivation as Mediator between Family Support to the Readiness of Pregnant Woman in Exclusive Breastfeeding
}

\author{
Sri Mulyani ${ }^{1}$, A. A. Subiyanto ${ }^{1}$, Sapja Anantanyu ${ }^{1}$, Supriyadi Heri Respati ${ }^{2}$, Budiyanti \\ Wiboworini $^{1}$ \\ ${ }^{1}$ Faculty of Medicine Universitas Sebelas Maret, Indonesia \\ ${ }^{2}$ Department of Obstetrics Gynecology, Hospital Dr. Moerwadi-Surakarta, Indonesia
}

\begin{tabular}{l} 
Article Info \\
\hline Article history: \\
Received Mar 13, 2017 \\
Revised May 14, 2017 \\
Accepted May 29, 2017 \\
\hline
\end{tabular}

\section{Keywords:}

Exclusive breastfeeding

Family support

Motivation

Readiness

\begin{abstract}
The success of the implementation of exclusive breastfeeding in the community is depending on the readiness of pregnant mothers in exclusive breastfeeding. This readiness is influenced by several factors including motivation and support exclusive breastfeeding by family. This study aimed to examine the empirical model that shows the motivational role as mediators of the relationship between family supports of readiness pregnant mothers in exclusive breastfeeding. Cross-sectional study performed on pregnant women in Surakarta. There were 150 mothers in her first time pregnancy participated in this study. The closed questionnaire of Likert scale developed to measure three variables of the study. Path analysis procedure used to test the hypothesis of motivational role as mediator relations between two other variables. The results showed that all three variables had a significant relation $(\mathrm{p}<0.001)$. The relationship between family support to readiness pregnant women after entering motivation as covariates remained significant but decreased significantly path coefficient $(\beta=0.365 ; \mathrm{p}<0.001$ becomes $\beta=0.260 ; p=0.001$ ). Thus the motivation becomes a mediator relationship with the family support of readiness pregnant mothers in exclusive breastfeeding.
\end{abstract}

Copyright (C) 2017 Institute of Advanced Engineering and Science. All rights reserved.

\section{Corresponding Author:}

Sri Mulyani,

Diploma Program in Midwifery, Faculty of Medicine,

Sebelas Maret University,

Surakarta, Indonesia.

Email: yaniarta@yahoo.com

\section{INTRODUCTION}

Motivation is a collection of psychological causes movement, direction, and persistence of voluntary attitudes that lead to the goal [1]. According to Victor motivation is the consequence of a result of being pursued by someone, if someone wants something and hope to get something that is big enough, the question will be highly motivated to obtain the things they want it. Conversely, if the hope of things they want was thin, his motivation to attempt to be low [2]. In this study the prospect means the desire of pregnant women in order to succeed in providing exclusive breastfeeding the infants who will be born, so it needs to be an effort both physically and psychologically and have strength inside which causes the movement, direction, effort and persistence to face the obstacles [1,2].

Family support has a relation to the successful of exclusive breastfeeding. One type of family support is giving a material assist [3], physical assistance or any other type of device to support and help mothers in breastfeeding. The family and the husband must provide encouraging support to the mother through the words of praise, and the words of encouragement, so that mothers feel proud and happy to be able to provide breast milk to the baby $[4,5]$. The supporting statement delivered by Bobak, et. al, that a 
husband's support to breastfeeding mothers is no criticism of her body shape which generally are stretched after childbirth $[6,7]$.

Husband's involvement in breastfeeding, will increase the confidence of the mother and the environment. Thus, the mother will be protected from insecurity, worry, anxiety that can lead to the decline in production of the oxytocin hormone which the oxytocin hormone is an important hormone for breast milk production [8]. The decrease in the production of this hormone can result in a decline in breast milk production due to the drainage of breast milk substandard and will cause disruption of the process of lactation [9].

Readiness by Ohnishi is a form of maturity for someone to face a new situation and one of the important things that must be owned by a person to decide things [10,11]. The decision to breastfeed or not is performed since they are pregnant or before having children [12, 13]. Readiness mother in exclusive breastfeeding is the attitude and behavior of the mother is a form of maturity owned by the mother to decide and have the readiness to exclusive breastfeeding [14].

Readiness breastfeeding during pregnancy is important, mothers who prepare early will be better prepared to breastfeed her baby $[15,16]$. Indicators of readiness the mothers in exclusive breastfeeding in this study include: (a) the readiness of the health of the mother, it is a form of attitude and behavior of the mother in keeping her health during pregnancy, (b) psychological readiness mother, expected mother has the intention and self-confidence will be her ability to give exclusive breastfeeding [17]. Thus the mother will think optimistic and positive which will affect the readiness of all the organs of breast-feeding so that the milk flowed smoothly, (c) nutrition/nutrition of pregnant women, during pregnancy nutrition is one of the important factors that determine the success of breastfeeding, (d) the readiness of the breast, several unsuccessful breastfeeding is due to an obstruction on the mother's nipple so the breast milk can not be removed and will have an impact on the decline in breast milk production [18], (e) the readiness of the health infants, babies healthy and in the normal conditions will be able to absorb the nipple strongly, it is very important to stimulate the prolactin and oxytocin hormone [19].

\section{RESEARCH METHOD}

Cross-sectional study performed on pregnant women who live in the city of Surakarta. During the observation made in 2015 through 2016 were taken a sample of 150 respondents. Measurement of the variables used the enclosed questionnaire in each item questions rated by Likert scale. Motivation is measured by three indicators, namely support, effort, and persistence. Family support is measured by three indicators, namely mentoring, attention and assistance. Readiness is measured by five indicators of maternal health preparedness, maternal psychological preparedness, readiness of the breast, nutrition / maternal nutrition and infant health preparedness. Each indicator is expressed in some of the items the question that has been validated both in terms of language or sentence structure (content validity) as well as the side of the construct. All constructs (variables) also has a high reliability (Cronbach's alpha>0.9).

Relations between variables were analyzed in the simplest form of the structural model with path analysis. Intermediate variables criteria expressed as a mediator between the independent variables and the dependent variable is when the relationship between the three significant variables and the influence of the independent variable on the dependent variable decreases significantly when the intermediate variables included as covariates (independent variables together). Data processing was performed using SPSS for Windows 13 version. Statistical testing is done with a significance level of $5 \%$.

\section{RESULTS AND ANALYSIS}

The demographic characteristics of respondents most commonly found are aged 21-25 years $(64.0 \%)$, do not work or only as a housewife (56.7\%), just married less than 2 years $(68.0 \%)$, and lives with her husband and both parents or parent in-laws (62.7\%). Description of the characteristics of respondents can be seen in Table 1.

Been mentioned before that the criteria for intermediate variables $(Z)$ is expressed as a mediator between the independent variables $(\mathrm{X})$ and the dependent variable $(\mathrm{Y})$ is when the relationship between the three significant variables and the influence of the independent variable on the dependent variable decreases significantly when the intermediate variables entered as covariates. To test this criteria then carried four regression analysis, namely:
1. $\mathrm{X}$ to $\mathrm{Y}$
2. $X$ to $Z$
3. Z to $\mathrm{Y}$, and
4. $\mathrm{X}$ and $\mathrm{Z}$ to $\mathrm{Y}$. 


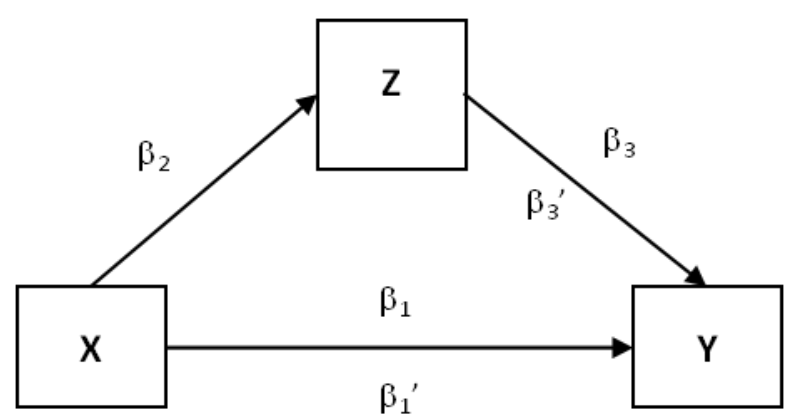

Figure 1. Structural Model with Path Analysis for Relations Mediation

Table 1. Characteristics Description Respondents

\begin{tabular}{cccc}
\hline Characteristics & F & $\%$ \\
\hline Age & & \\
16-20 years old & 11 & 7.3 \\
21-25 years old & 96 & 64.0 \\
26-30 years old & 38 & 25.3 \\
31-35 years old & 3 & 2.0 \\
36-40 years old & 2 & 1.3 \\
Employment Status Working & 65 & 43.3 \\
Not working & 85 & 56.7 \\
Long Marriage & & \\
< 2 years & 102 & 68.0 \\
2-5 & 44 & 29.3 \\
Years > 5 years & 4 & 2.7 \\
Status of Dwelling & & \\
With husband only & 56 & 37.3 \\
Together with parent / parent in-laws & 94 & 62.7 \\
\hline
\end{tabular}

Table 2. Estimated and Test Strip Coefficient Statistics for Path Analysis

\begin{tabular}{cccccc}
\hline No. & Regression Model & $\begin{array}{c}\text { Symbol } \\
\text { Coefficient }\end{array}$ & $\beta$ & $\mathrm{P}$ & Description \\
\hline 1. & $\mathrm{X} \rightarrow \mathrm{Y}$ & $\beta 1$ & 0.365 & $<0.001$ & Significant \\
2. & $\mathrm{X} \rightarrow \mathrm{Z}$ & $\beta 2$ & 0.312 & $<0.001$ & Significant \\
3. & $\mathrm{Z} \rightarrow \mathrm{Y}$ & $\beta 3$ & 0.415 & $<0.001$ & Significant \\
4. & $\mathrm{X} \rightarrow \mathrm{Y}$ & $\beta 1$ & 0.260 & $<.001$ & Significant \\
& $\mathrm{Z} \rightarrow \mathrm{Y}$ & $\beta 3$ & 0.334 & $<.001$ & Significant \\
\hline
\end{tabular}

Notes: $\mathrm{X}=$ family support; $\mathrm{Z}=$ motivation in exclusive breastfeeding; $\mathrm{Y}=$ readiness in exclusive breastfeeding.

In Table 2 are presented the results of estimations and statistical test path coefficient $(\beta)$ to the path analysis of regression based on four models that have been determined. The relationship between variables in the first model $\left(\beta_{11}=0.365\right)$, the second model $\left(\beta_{22}=0.312\right)$, and the third model $\left(\beta_{33}=0.415\right)$ was significant $(p<0.001)$ so that the first three conditions are met mediation relationship. In the fourth model of the relationship between motivation and readiness in exclusive breastfeeding was significant $\left(\beta_{3}{ }^{\prime}=0.334\right.$; $\mathrm{p}<0.001)$. The relationship between family readiness support pregnant women in exclusive breastfeeding also significant $\left(\beta_{1}^{\prime}=0.260 ; p<0.001\right)$. The relations between these two variables significantly better in the first model (without motivation as covariates) and the fourth model (with motivation as covariates). Despite that there is a decline path coefficient of 0.365 into 0.260 . Mathematically quantifiable decrease in the influence of family support on the readiness of the mother as follows:

$$
\frac{\left(\beta_{1}\right)^{2}-\left(\beta_{1}^{\prime}\right)^{2}}{\left(\beta_{1}\right)^{2}} \times 100 \%=\frac{(0.365)^{2}-(0.260)^{2}}{(0.365)^{2}} \times 100 \%=49.3 \%
$$

The decrease of influence family support on the readiness of pregnant women almost reached $50 \%$. The decline in considerable contribution shows that the fourth condition is fulfilled mediation relationship. Thus can be concluded that the motivation of pregnant women in exclusive breastfeeding can mediate the relationship between family support to the readiness of pregnant women in exclusive breastfeeding 
The results of this research showed that there is a role mediating of mother's motivation in exclusive breastfeeding in the relationship between family support and the readiness of pregnant mothers in exclusive breastfeeding. The implication, family support and motivation of pregnant mothers in exclusive breastfeeding will encourage its readiness to exclusive breastfeeding. But the family support factors can have a direct or indirect influence. The direct effect is shown with the condition when women received good support from family then it will directly lead her for getting ready to give exclusive breast feeding [20]. The indirect effect is shown by the conditions when a good support from family at the beginning is compose or enhance motivation of mothers in exclusive breastfeeding. Furthermore, if the mother has a high motivation then she will tend to be better prepared to give exclusive breastfeeding.

Empirical models are analyzed in this study is based on the concept of Green Precede-Procede. Green identifies three categories of factors that have a direct impact on the health and environmental behavior are the predisposing factors, a likely factor, and support factor [21]. Readiness to give exclusive breastfeeding is one form of health behaviors, while motivation is one of the predisposing factors and family support is one factor which support the behavior. Family support can influence indirectly on the readiness but by first forming maternal motivation. The support of a husband who firmly think that breast milk is the best, will make the mothers exclusively breastfeed their babies easily [22]. One type of family support is giving materials assistance, physical assistance or any other form of device support and helping mothers in breastfeeding. The presence of family is very important to encourage mothers to boost confidence and stabilize her emotions, and also providing a great motivation to breastfeeding women. In fact the influence of family support indirectly as forming the motivation is often greater contribution in encouraging the readiness pregnant mothers in exclusive breastfeeding. This is because the motivation is a predisposing behavior factors and predisposing factors arise from inside the person and become a beginning and primary shaper of behavior.

\section{CONCLUSION}

The conclusion from this study is the motivation of pregnant mothers in exclusive breastfeeding may have a role as a mediator of the relationship between family supports to the readiness of pregnant mothers in exclusive breastfeeding. Based on this conclusion in order to the implementation of exclusive breastfeeding successfully so the family (especially the husband) is highly recommended to provide the best support for the mother not to help the readiness of the mother but rather as a motivator for pregnant mothers in exclusive breastfeeding.

\section{REFERENCES}

[1] J. Robbins, "Organizational behavior," translation. Diana Angelica, Jakarta, Salemba Four, 2007.

[2] F. Luthan, "Organizational Behavior; an Evidance-Based Apprach," New York, Mc Graw Hill Book Company, 2011.

[3] T. Amin, et al., "Determinants of Initiation and Exclusivity of Breastfeeding in Al Hassa, Saudi Arabia," Journal Breastfeed Med, vol. 6. pp. 59-68, 2011.

[4] M. Meiliasari, "Breastfeeding Is Not Just Mom's Duty,” Jakarta, EGC, 2012.

[5] Maharaj N. and Bandyopadhyay M., "Breastfeeding Practices of Ethnic Indian Immigrant Women in Melbourne, Australia," Journal International Breastfeeding, vol. 17 pp. 1-9, 2013.

[6] L. Bobak and Jansen, "Maternity Nursing Teaching Textbook (translation ed.4)," Jakarta, EGC, 2005.

[7] Youlin Q., et al., "Maternal and Breast Pump Factors Associated with Breast Pump Problems and Injuries," Journal of Human Lactation, vol. 30 pp. 62-72, 2014.

[8] A. F. Jorm, "Mental Health Disorders," British Journal of Psychiatry, vol. 177, pp. 396-401, 2000.

[9] Jessica A., et al., "Using mPINC Data to Measure Breastfeeding Support for Hospital Employees," Journal of Human Lactation, vol. 30, pp. 97-101, 2014.

[10] M. Ohnishi, et al., "Improvement In Maternal Health Literacy Among Pregnant Women Who Did Not Complete Compulsory," The CDC Guide to Breastfeeding Intervention. U.S Departemen of Health \& Human Services Center for Disease Control and Prevention National Center for Cronic Disease Prevention and Health Promotion Division of Nutrition and Physical Activity, 2005.

[11] S. Kohan, et al., "Association between maternal health literacy and prenatal care and pregnancy outcome," Iranian Journal of Nursing and Midwifery Research, vol/issue: 12(4). pp. 146-152, 2007.

[12] I. S. Kickbusch, "Health literacy: Addressing the Health and Education Divide," Health Promotion International Journal, vol/issue: 16(5), pp. 289-297, 2001.

[13] S. U. Lin-Lin, et al., "Antenatal Education and Postnatal Support for Improving Rates of Exclusive Breast Influence of Maternal Health Literacy on Healthy Pregnancy \& Pregnancy Outcomes Feeding: Randomised Control Trial," British Medical Journal, vol/issue: 335(7620), pp. 596-599, 2007.

[14] L. W. Green and M. W. Kreuther, "Health Program Planning: an Educational and Ecological Approach," New 
York, McGraw-Hill, 2005.

[15] Rema R., et al., "The Association between Maternal Perception of Obstetric and Pediatric Care Providers' Attitudes and Exclusive Breastfeeding Outcomes," Journal of Human Lactation, vol. 30, pp. 80-87, 2014.

[16] C. Man-Ku and Chow, "Factors Influencing the Practice of Exclusive Breastfeeding among Hongkong Chinese Women: A questionnaire Survey," Journal of Clinical Nursing, vol. 19, pp. 2434-2445, 2010.

[17] M. Anthony, et al., "Determinants of Exclusive Breastfeeding among Mothers in Ghana: A Cross-Sectional Study," Journal International Breastfeeding, vol. 8, pp. 1-13, 2013.

[18] G. Binns, et al., "Factors Assocated Whith Initiation of Breast-Feeding by Aboriginal Mother in Perth," Journal Public Health Nurt, vol. 45, pp. 174-180, 2004.

[19] Singh G. K., et al., "Nativity/Immigrant Status, Race/Ethnicity and Socioeconomic Determinants of Breastfeeding Initiation and Duration in the United States," J Pediatrics, vol. 119, pp. 38-46, 2007.

[20] Wenzel D., et al., "A Multilevel Model for the Study of Breasfeeding Determinants in Brazil,” Journal Matern Child Nurt, vol. 6, pp. 318-327, 2010.

[21] S. Purwoko, "Breastfeeding Practical, Easy \& Comfortable," Jakarta, EGC, 2005.

[22] Tesfaye S., et al., "Factors Associated with Exclusive Breastfeeding Practices among Mothers in Goba District, South East Ethiopia: a Cross-Sectional Study,” J International Breastfeeding, vol/issue: 7(17), pp. 1-9, 2012.

\section{BIOGRAPHIES OF AUTHORS}
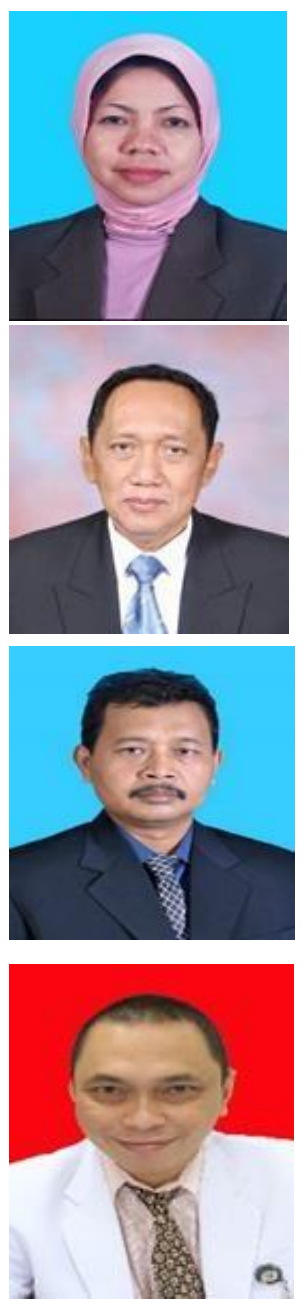

Sri Mulyani, S.Kep, Ns, M.Kes. is Lecturer of Diploma Program in Midwifery Faculty of Medicine, Sebelas Maret University in Surakarta, Central Java, Indonesia. Currently she is the leader of research group of mother and childrens's health in Sebelas Maret University.

Prof. Dr. dr Ahmad Arman Subiyanto, MS. is Lecutrer of Masters Program in Family Medicine, Sebelas Maret University in Surakarta, Central Java, Indonesia. Currently he is the head of Study Program of Family Medicine in Masters Program of Sebelas Maret University.

Dr. Sapja Anantanyu, M.Si. is Lecturer of Doctoral Program in Development Promotion, Sebelas Maret University in Surakarta, Central Java, Indonesia. Currently he is the Head of Doctoral Program of Development/Empowerment in Masters Program of Sebelas Maret University.

Dr. dr. Supriyadi Heri Respati, Sp.OG (K). is an Obstetry and Gynecology doctor in Department of Obstetry and Gynecology, Dr. Moewardi Hospital in Surakarta, Central Java, Indonesia 


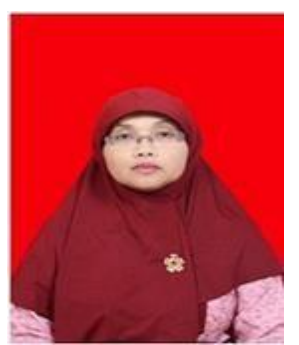

Dr. dr. Budiyanti Wiboworini M.Kes, Sp.Gk. is a Lecturer of Medical Faculty, Sebelas Maret University, Central Java, Indonesia. Currently she is First Vice Dean in Medicine Faculty of Sebelas Maret University. 